\title{
MUTAGENICITY IN THE SPERM OF DROSOPHILA AND THE STRUCTURE OF THE "NITROGEN-MUSTARD " MOLECULE
}

\author{
O. G. FAHMY and MYRTLE J. FAHMY \\ Chester Beotty Reseorch Institute, Institute of Concer Research: \\ Royal Concer Hospital, London, S.W. 3
}

\section{INTRODUCTION}

Received 12.ii.6o

A profitable approach to the elucidation of the molecular mechanism of mutagenesis is through the comparative analysis of the biochemical and mutagenic properties of related compounds. In recent years attention has been centred on the study of the biochemical mode of action of the alkylating agents in general and the "mustards" in particular (Ross, I953; Bergel, 1955). This communication deals with the relative mutagenic potency on the mature sperm of a series of closely related " nitrogen-mustards". The study has been restricted to the sperm, since the response of this stage provides the best biological measurement of the direct interaction between the mutagen and the genic material. Mutagenicity in the sperm must be the outcome of reactions within the hereditary nucleoproteins, since this cell-stage consists of highly condensed chromosomes with practically no surrounding cytoplasm. Furthermore, the sperm is anabolically inert, in the sense that its chromosomes do not undergo replication. This eliminates from the test system the complications of nucleoprotein synthesis and minimises the role of metabolic transport.

The compounds studied are difunctional aryl-2-chloroethylamines, with various substitutions designed to alter the non-alkylating, or prosthetic, moeity of the molecule to amino-acids, carboxylic acids and amines. An assay of the relationship between dose and mutation rate was made for the various compounds with a view to the assessment of mutagenic potency in relation to molecular configuration. There was ample evidence that mutagenic activity does not only depend on the reactivity of the alkylating groups, but also on the nature of the prosthetic moeity.

\section{MATERIAL AND TECHNIQUE}

The series of "nitrogen-mustards" analysed in this communication were synthesised in the Chemistry Department (for references see review by Bergel, 1955) in relation to cancer chemotherapy. Representatives of this series were subjected to various biological tests and it soon became cvident that they possess carcinogenic activity (in mice and rats), as well as decisive tumour inhibitory effects (both in experimental animals and in man : see review by Haddow, 1955). These agents also proved to be strong mutagens and various aspects of their mutagenic properties have already been reported (Bird and Fahmy, 1953; Fahmy and Fahmy, 1956, $1959,1960 a$ and $b$ ). For ease of reference, the chemical names and formulæ, as well as the (CB.) code numbers of the compounds tested will be listed here. 
Phenylamino-acid mustards.

CB. 3025 : (Melphalan).

$\left(\mathrm{ClCH}_{2} \mathrm{CH}_{2}\right)_{2} \mathrm{~N} \cdot \mathrm{C}_{6} \mathrm{H}_{4} \cdot \mathrm{CH}_{2} \mathrm{CHNH}_{2} \mathrm{COOH}$

$p$-NN-di(2-chloroethyl)amino- $L$-phenylalanine.

CB. 3026 : The D-isomer (Medphalan).

CB. 3007 : The DL-mixture (Merphalan).

CB. 1385 : $\left(\mathrm{ClCH}_{2} \mathrm{CH}_{2}\right)_{2} \mathrm{~N} \cdot \mathrm{C}_{6} \mathrm{H}_{4} \cdot \mathrm{CH}_{2} \mathrm{CH}_{2} \mathrm{CHNH}_{2} \mathrm{COOH}$

$\alpha$-amino- $\gamma-p-(\mathrm{NN}-d i-2$-chloroethyl amino) phenylbutyric acid.

Phenylcarboxylic acid mustards.

$\left(\mathrm{ClCH}_{2} \mathrm{CH}_{2}\right)_{2} \mathrm{~N} \cdot \mathrm{C}_{6} \mathrm{H}_{4} \cdot\left(\mathrm{CH}_{2}\right)_{n} \mathrm{COOH}$

CB. I33I : $n=\mathbf{I}, p$-NN-di-(2-chloroethyl)aminophenylacetic acid.

CB. I332: $n=2, p$-NN-di-(2-chloroethyl)aminophenylpropionic acid.

CB. 1348 : (Chlorambucil)

$n=3, p-\mathrm{NN}$-di-(2-chloroethyl)aminophenylbutyric acid.

CB. I356: $n=4, p$-NN-di-(2-chloroethyl)aminophenylvaleric acid.

Phenylethylamine mustard.

CB. 3034 : $\left(\mathrm{ClCH}_{2} \mathrm{CH}_{2}\right)_{2} \mathrm{~N} \cdot \mathrm{C}_{6} \mathrm{H}_{4} \cdot \mathrm{CH}_{2} \mathrm{CH}_{2} \mathrm{NH}_{2}$ $p$-NN-di-(2-chloroethyl) aminophenylethylamine.

For the mutagenicity tests, the above compounds were administered by our micro-injection technique into adult Drosophila melanogaster males of the Oregon-K stock. Previous experience has shown that the best quantitative results as regards mutagenicity are obtained when the mutagens are administered in aqueous solutions. The amine-mustard (CB. 3034) was injected in solution as the hydrochloride. The carboxylic and amino-acid mustards were converted to the sodium salts and were in complete solution at the concentrations utilised in the present experiments. It should be noted, however, that the sodium salts hydrolyse readily in water, giving the biologically inactive hydroxyl derivatives. This necessitated the preparation of a fresh sample of the sodium salt for each experiment, just before administration.

Males were subjected to treatment at an age of $30 \pm 5$ hours after eclosion. About 200-500 males were selected for each experiment, and they were then partially dewinged, and weighed on an analytical chemical balance. In the present experiments, the average weight per male was $0.85 \pm 0.05 \mathrm{mg}$. A solution of the compound at the desired concentration was then injected by a calibrated micrometer syringe, around and within the testes of the weighed males. Each fly was given the same volume of solution, as gauged by the dial of the micrometer screw operating the plunger of the syringe. The injected males were then reweighed. The weight before and after injection enables the determination of the average weight injected per male, which for dilute solutions is roughly equal to the volume. The weighing procedure provided a check on the delivery of the micro-syringe. In the present experiments the average volume of solution received per male was of the order of $0.3 \mu 1$.

The mutations analysed in this communication are the sex-linked recessive lethals detected by the Muller-5 technique (details in Fahmy and Fahmy, 1955). The present analysis has been restricted to the progeny of the treated males recovered o-3 days after treatment. This is to ensure that the mutation rates assayed represent the response of mature sperm.

\section{EFFECT OF DOSE}

An analysis of the dose effect under a given mutagen necessitates the consideration of the "natural" or spontaneous mutation rate (corresponding to zero dose). Males of the same average size and weight as those utilised in the mutagenicity tests were injected with 
isotonic saline $(0.4$ per cent. $\mathrm{NaCl})$ and their progeny (during the first 3 days after treatment) were tested for sex-linked recessive lethals. In five control experiments undertaken concomitantly with the present series of compounds an overall sample of 2402 X-chromosomes

TABLE I

The mulagenicity of the mustard derivatives of phenylalanine in relation to the injected dose

\begin{tabular}{|c|c|c|c|c|}
\hline \multirow{2}{*}{$\begin{array}{l}\text { Concentration } \\
\left(\times 10^{-2} \mathrm{M}\right)\end{array}$} & \multirow{2}{*}{ Isomer } & \multirow{2}{*}{$\begin{array}{l}\text { Chromosomes } \\
\text { tested }\end{array}$} & \multicolumn{2}{|c|}{ Lethals } \\
\hline & & & No. & $\begin{array}{l}\text { Per cent. } \\
\text { (corrected) }\end{array}$ \\
\hline 0.5 & $\begin{array}{c}\text { CB. } 3007 \\
, ?\end{array}$ & $\begin{array}{l}406 \\
45^{8}\end{array}$ & $\begin{array}{r}13 \\
7\end{array}$ & $\begin{array}{l}2 \cdot 9 \\
\mathrm{I} \cdot 2\end{array}$ \\
\hline 0.8 & $\begin{array}{l}\text { CB. } 3025 \\
\text { CB. } 3026 \\
\text { CB. } 3007\end{array}$ & $\begin{array}{l}588 \\
559 \\
466\end{array}$ & $\begin{array}{l}\text { I } 7 \\
\text { I } 9 \\
\text { I I }\end{array}$ & $\begin{array}{l}2 \cdot 6 \\
3 \cdot I \\
2 \cdot I\end{array}$ \\
\hline 0.9 & $\begin{array}{c}\text { CB. } 3^{025} \\
, " \\
", \\
", \\
\text { CB. } \\
\text { CB. } 3^{026} 6\end{array}$ & $\begin{array}{l}564 \\
355 \\
328 \\
360 \\
342 \\
345 \\
5 \text { I } 5 \\
202 \\
377\end{array}$ & $\begin{array}{l}42 \\
14 \\
22 \\
19 \\
19 \\
20 \\
26 \\
14 \\
43\end{array}$ & $\begin{array}{r}7 \cdot 1 \\
3 \cdot 6 \\
6 \cdot 4 \\
5 \cdot 0 \\
5 \cdot 3 \\
5 \cdot 5 \\
4 \cdot 7 \\
6 \cdot 6 \\
I I \cdot I\end{array}$ \\
\hline $\mathrm{I} \cdot 07$ & $\begin{array}{c}\text { CB. } 3025 \\
" " \\
" \\
\text { CB. } \\
\text { "3026 } \\
" "\end{array}$ & $\begin{array}{r}45 \mathrm{I} \\
396 \\
74 \\
235 \\
482 \\
46 \mathrm{I}\end{array}$ & $\begin{array}{r}\mathrm{I} 5 \\
33 \\
6 \\
33 \\
3 \mathrm{I} \\
34\end{array}$ & $\begin{array}{r}3 \cdot 0 \\
8 \cdot 0 \\
7 \cdot 8 \\
13 \cdot 7 \\
6 \cdot 1 \\
7 \cdot 1\end{array}$ \\
\hline$I \cdot 2$ & $\begin{array}{c}\text { CB. } 3025 \\
\text { CB. } 3026 \\
\text { CB. } 3007 \\
, y\end{array}$ & $\begin{array}{l}53 \text { I } \\
\text { I IO } \\
555 \\
34^{2}\end{array}$ & $\begin{array}{l}29 \\
16 \\
12 \\
18\end{array}$ & $\begin{array}{r}5 \cdot 2 \\
14 \cdot 2 \\
1 \cdot 9 \\
5 \cdot 0\end{array}$ \\
\hline$I \cdot 5$ & $\begin{array}{c}\text { CB. } 3025 \\
\text { C.B. } 3^{026} \\
\text { CB. } 3^{007} \\
\text { "y }\end{array}$ & $\begin{array}{r}255 \\
78 \\
176 \\
434\end{array}$ & $\begin{array}{r}15 \\
7 \\
22 \\
41\end{array}$ & $\begin{array}{r}5 \cdot 6 \\
8 \cdot 7 \\
12 \cdot 2 \\
9 \cdot 1\end{array}$ \\
\hline
\end{tabular}

were tested and 7 were found to carry lethals, a rate of $0 \cdot 3$ per cent. This value is in conformity with the spontaneous rate in the sperm repeatedly ascertained for our stock. It has, therefore, been used as a correction factor in the assessment of the induced mutation rates.

(i) The mustard derivatives of phenylalanine

The most extensive analysis of the effect of dose on the mutation rate was undertaken with the mustard derivatives of phenylalanine 
(table I). The data with this compound, however, proved to be heterogeneous. This was mainly due to the necessity of using different samples in the various experiments because of the speedy hydrolysis of the sodium salt (half life in neutral solution at room temperature $\simeq 3$ hours). Different samples, even at the same dose, showed varied biological activity as regards toxicity, fertility and mutagenicity. The size of the progeny and in turn the number of chromosomes available for the genetic tests, have accordingly varied in the different

TABLE 2

Statistical analysis of the mutagenicity of the mustard derivative of phenylalanine. The regression of ihe lethal rate $(y:$ in probits) on dose $(x:$ in $\log$ units, log conc. +1$)$

A. Significance and linearity of the regression

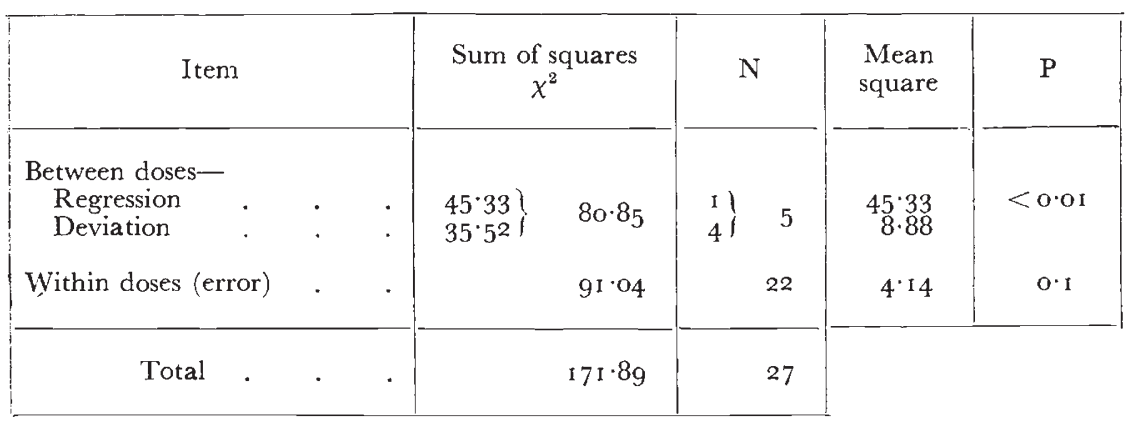

B. Isomer effect : covariance of $x$ and $y$

\begin{tabular}{|c|c|c|c|c|c|c|}
\hline \multirow{2}{*}{ Item } & \multicolumn{3}{|c|}{$V y$ before correction } & \multicolumn{2}{|c|}{$V y$ after correction } & \multirow{2}{*}{$\begin{array}{l}\text { Mean } \\
\text { square }\end{array}$} \\
\hline & $\mathrm{N}$ & s.sq. & Reg. $y$ on $x$ & Remainder & $\mathrm{N}$ & \\
\hline $\begin{array}{l}\text { Between isomers } \\
\text { Within isomers }\end{array}$ & $\begin{array}{r}2 \\
25\end{array}$ & $\begin{array}{r}I \cdot 54 \\
\text { I } 70 \cdot 35\end{array}$ & $4 \underset{6 \cdot 03}{ }$ & $\begin{array}{r}2 \cdot 24 \\
124 \cdot 32\end{array}$ & $\begin{array}{r}2 \\
24\end{array}$ & $\begin{array}{l}I \cdot 12 \\
5 \cdot 18\end{array}$ \\
\hline Total & 27 & I $71 \cdot 89$ & $45 \cdot 33$ & $126 \cdot 56$ & 26 & \\
\hline
\end{tabular}

experiments. Furthermore, 3 different isomeric forms were used: the L-isomer (CB. 3025), the D-isomer (CB. 3026) and the racemic mixture (CB. 3007). In the assay of the mutagenic potency of this compound, therefore, it is essential $(a)$ to give due weight to the various mutation estimates, $(b)$ allow for the uncontrollable variation in replications and $(c)$ assess the significance of the isomer effect.

The statistical analysis of the dose effect was undertaken by the regression technique. A double transformation has been used: the proportion of lethal chromosomes into probits and that of dose into log dose. To ease calculation by removing negative signs from the $\log$ values, the independent variate $(x)$ was taken as log concentration +1. A weighted regression of the mutation rate $y$ (in probits) on $x$ 
was then fitted to the data (Fisher and Yates, 1953, section 7.I). The items for this regression are entered in table 4 and the analysis of goodness of fit is given in table $2 \mathrm{~A}$. The regression, though accounting for a large and very significant sum of squares $\left(\chi^{2}=45.3\right.$ for I degree of freedom), still leaves a major error item $\left(\chi^{2}=126 \cdot 6\right.$ for 26 degrees of freedom). Clearly the theoretical variance is much too small and must be rejected in favour of the experimental variance within replications at the various doses. This item of the error was isolated by

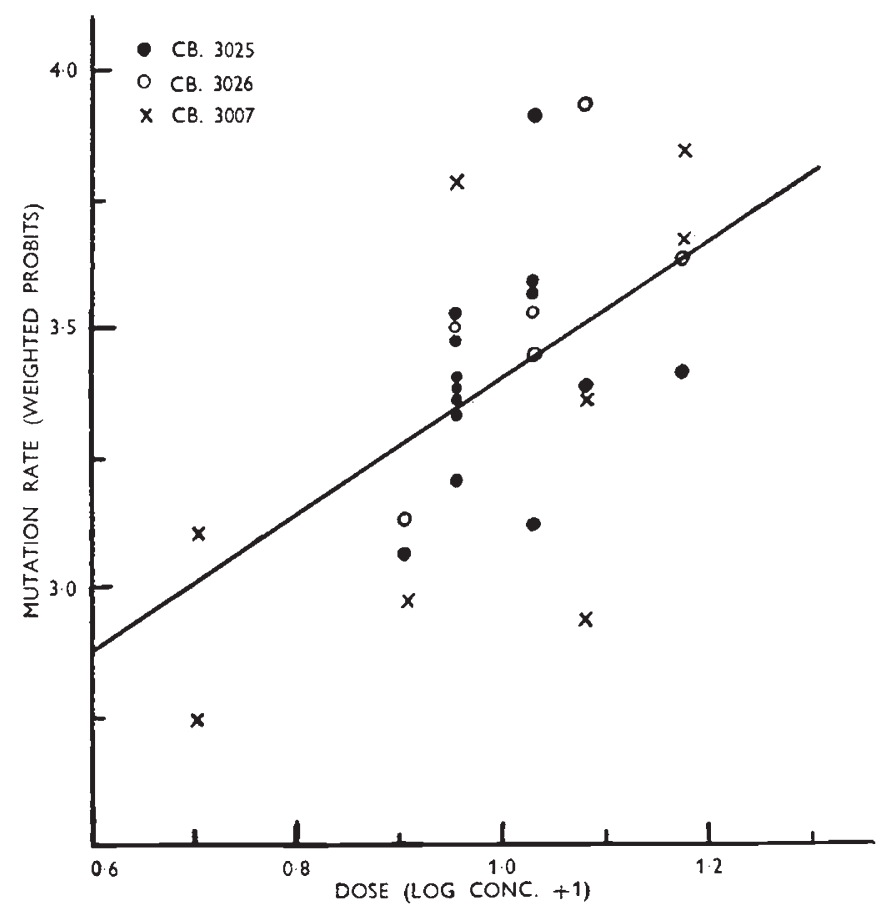

FIG. 1.-The regression of mutation rate in probits on dose in log units, under the mustard derivatives of phenylalanine.

pooling the sum of squares around the mean mutation rates at the separate doses. It can be seen from table $2 \mathrm{~A}$ that the regression item compared to the within doses error corresponds to $t=3 \cdot 309$, which for 22 degrees of freedom is decisively significant $(\mathrm{P}<\mathrm{O} \cdot \mathrm{OI})$. Of greater interest is the fact that the mean square for the dose effect which is unaccounted for by the regression is not significantly higher than the error within replications $(P \simeq 0 \cdot I)$. This shows that the calculated linear regression is a satisfactory representation of the data.

To test the isomer effect, a different partition of the sum of squares of $y$ was necessary. The difference in the dose values $(x)$ used with the 3 isomeric forms, necessitated a consideration of the variance of $x$ and the covariance of $x$ and $y$. This analysis was undertaken according to Mather's (1949, section 34) method, and is summarised in table 28. The mean square between isomers (after correction 
for dose differences) is substantially lower than that within isomers. It can, therefore, be concluded that the present set of data do not reveal any difference in the mutagenicity of the various isomers on the mature sperm.

TABLE 3

The mutagenicity of various " nitrogen-mustards" in relation to dose

\begin{tabular}{|c|c|c|c|c|}
\hline \multirow{2}{*}{ Mutagen } & \multirow{2}{*}{$\begin{array}{c}\text { Concentration } \\
\left(\times 10^{-2} \mathrm{M}\right)\end{array}$} & \multirow{2}{*}{$\begin{array}{l}\text { Chromosomes } \\
\text { tested }\end{array}$} & \multicolumn{2}{|c|}{ Lethals } \\
\hline & & & No. & $\begin{array}{l}\text { Per cent. } \\
\text { (corrected) }\end{array}$ \\
\hline CB. 3034 & $\begin{array}{l}0 \cdot 19 \\
0 \cdot 29 \\
0 \cdot 3^{8} \\
0 \cdot 77 \\
-\cdot 15\end{array}$ & $\begin{array}{r}417 \\
388 \\
419 \\
62 \\
43\end{array}$ & $\begin{array}{r}17 \\
16 \\
29 \\
8 \\
7\end{array}$ & $\begin{array}{r}3 \cdot 8 \\
3 \cdot 8 \\
6 \cdot 6 \\
\mathbf{1} 2 \cdot 6 \\
\mathbf{1} 6 \cdot 0\end{array}$ \\
\hline CB. 1348 & $\begin{array}{l}0.2 \\
0.6 a \\
\quad b \\
\mathbf{1} \cdot 0\end{array}$ & $\begin{array}{l}424 \\
36 \mathrm{I} \\
249 \\
267\end{array}$ & $\begin{array}{l}\text { I2 } \\
19 \\
\text { I } 4 \\
33\end{array}$ & $\begin{array}{r}2 \cdot 5 \\
5 \cdot 0 \\
5 \cdot 3 \\
12 \cdot 1\end{array}$ \\
\hline CB. I33I & $\begin{array}{c}0 \cdot 3 \\
0 \cdot 7 a \\
b \\
\mathbf{I} \cdot 0\end{array}$ & $\begin{array}{l}458 \\
358 \\
261 \\
309\end{array}$ & $\begin{array}{l}13 \\
14 \\
12 \\
20\end{array}$ & $\begin{array}{l}2 \cdot 5 \\
3 \cdot 3 \\
4 \cdot 3 \\
6 \cdot 2\end{array}$ \\
\hline CB. $135^{6}$ & $\begin{array}{l}0.5 \\
0.7 \\
\text { I. }\end{array}$ & $\begin{array}{l}387 \\
317 \\
289\end{array}$ & $\begin{array}{r}8 \\
\text { I I } \\
\text { I } 3\end{array}$ & $\begin{array}{l}\mathrm{I} \cdot 8 \\
3 \cdot 2 \\
4 \cdot 2\end{array}$ \\
\hline CB. ${ }_{1385}$ & $\begin{array}{r}0 \cdot 3 \\
0 \cdot 5 \\
0 \cdot 7 a \\
b \\
\mathrm{I} \cdot 0 a \\
b\end{array}$ & $\begin{array}{r}273 \\
258 \\
189 \\
219 \\
112 \\
95\end{array}$ & $\begin{array}{l}4 \\
5 \\
3 \\
6 \\
4 \\
4\end{array}$ & $\begin{array}{l}\text { I } \cdot 2 \\
\text { I } 6 \\
\text { I } \cdot 3 \\
2 \cdot 4 \\
3 \cdot 3 \\
3 \cdot 9\end{array}$ \\
\hline CB. 1332 & $\begin{array}{l}0 \cdot 3 \\
1 \cdot 2 \\
1 \cdot 6\end{array}$ & $\begin{array}{l}356 \\
294 \\
258\end{array}$ & $\begin{array}{r}4 \\
6 \\
10\end{array}$ & $\begin{array}{l}0 \cdot 8 \\
1 \cdot 7 \\
3 \cdot 6\end{array}$ \\
\hline
\end{tabular}

The above considerations show that the 3 isomeric forms of the phenylalanine-mustard may be looked upon as one and the same compound. The dose effect relationship for this compound is adequately described as a direct linear increase in the mutation rate in probits with the increase in dose in log units (fig. I). It is also desirable to determine the exact relationship between the original (untransformed) variables, viz. the change in mutation rate with the injected molar concentration. For this purpose the best probit estimates 
corresponding to the experimental doses were converted to mutation rates (percentage lethals). These estimates were found to increase as the first power of the dose, indicating that the linear relationship holds equally true for the experimental variables.

\section{(ii) Other " nitrogen-mustards"}

The study of the dose effect was also undertaken for 6 other "mustards" (table 3). For each compound a weighted linear

TABLE 4

Items of the weighted linear regression $[Y=y+\mathbf{b}(\mathbf{x}-\bar{x})]$ for the variation in mutation rate (in probits) with dose (log conc. $+\mathrm{I}$ )

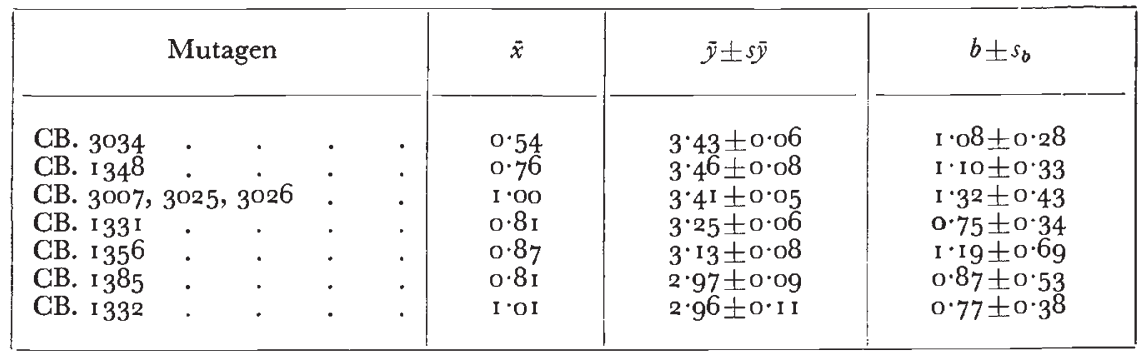

TABLE 5

Statistical analysis of the dose effect in the mutagenicity of various " nitrogen-mustards". The regression of the lethal rate $(y:$ weighted probits $)$ on dose $(x: \log$ conc. $+\mathrm{I})$

\begin{tabular}{|c|c|c|c|c|c|c|}
\hline \multirow{2}{*}{ Mutagen } & \multicolumn{3}{|c|}{ Regression } & \multicolumn{3}{|c|}{ Remainder (error) } \\
\hline & $x^{2}$ & $\mathrm{~N}$ & $P$ & $x^{2}$ & $\mathrm{~N}$ & $P$ \\
\hline CB. 3034 & $14 \cdot 58$ & I & 0.001 & I. 56 & 3 & $0.5-0.7$ \\
\hline CB. 1348 & $\begin{array}{l}19.13 \\
19.13\end{array}$ & I & 0.001 & 3.37 & $\begin{array}{l}3 \\
2\end{array}$ & $\begin{array}{ll}3 \\
0.1-0.2\end{array}$ \\
\hline CB. 1331 & $4.9 \mathrm{I}$ & I & $0 \cdot 02-0 \cdot 05$ & $\mathrm{I} \cdot 23$ & 2 & $0.5=0.7$ \\
\hline CB. 1356 & $2 \cdot 96$ & I & $0.05-0.1$ & 0.13 & I & $0.7-0.8$ \\
\hline CB. 1385 & $2 \cdot 72$ & I & $0.05-0 \cdot 1$ & I. 45 & 4 & $0.8-0.9$ \\
\hline CB. 1332 & 4.01 & I & $0.02-0.05$ & $0.9 \mathrm{I}$ & I & $0.3-0.5$ \\
\hline
\end{tabular}

regression was calculated for the variation in mutation rate in probits with the injected dose in $\log$ units (table 4). The goodness of fit for each line was also determined (table 5). For all compounds the linear regression accounted for the major part of the sum of squares of $y$, leaving a small and insignificant $\chi^{2}$ for the error, indicating the adequacy of the linear fitting. Fig. 2 illustrates the calculated regression lines for the various compounds in probits on log dose. For each compound the best mutation estimates (deduced from the regression and converted to percentages) were also found to increase linearly with the molar dose. 
(iii) Mutability at very low doses

An important question in relation to the variation in mutation rate with dose, is whether a threshold effect occurs under chemical mutagens. This problem resolves itself to testing whether the best fitting linear regression of mutation rate on dose could pass through the point of origin (i.e. extrapolated to zero dose). This cannot easily

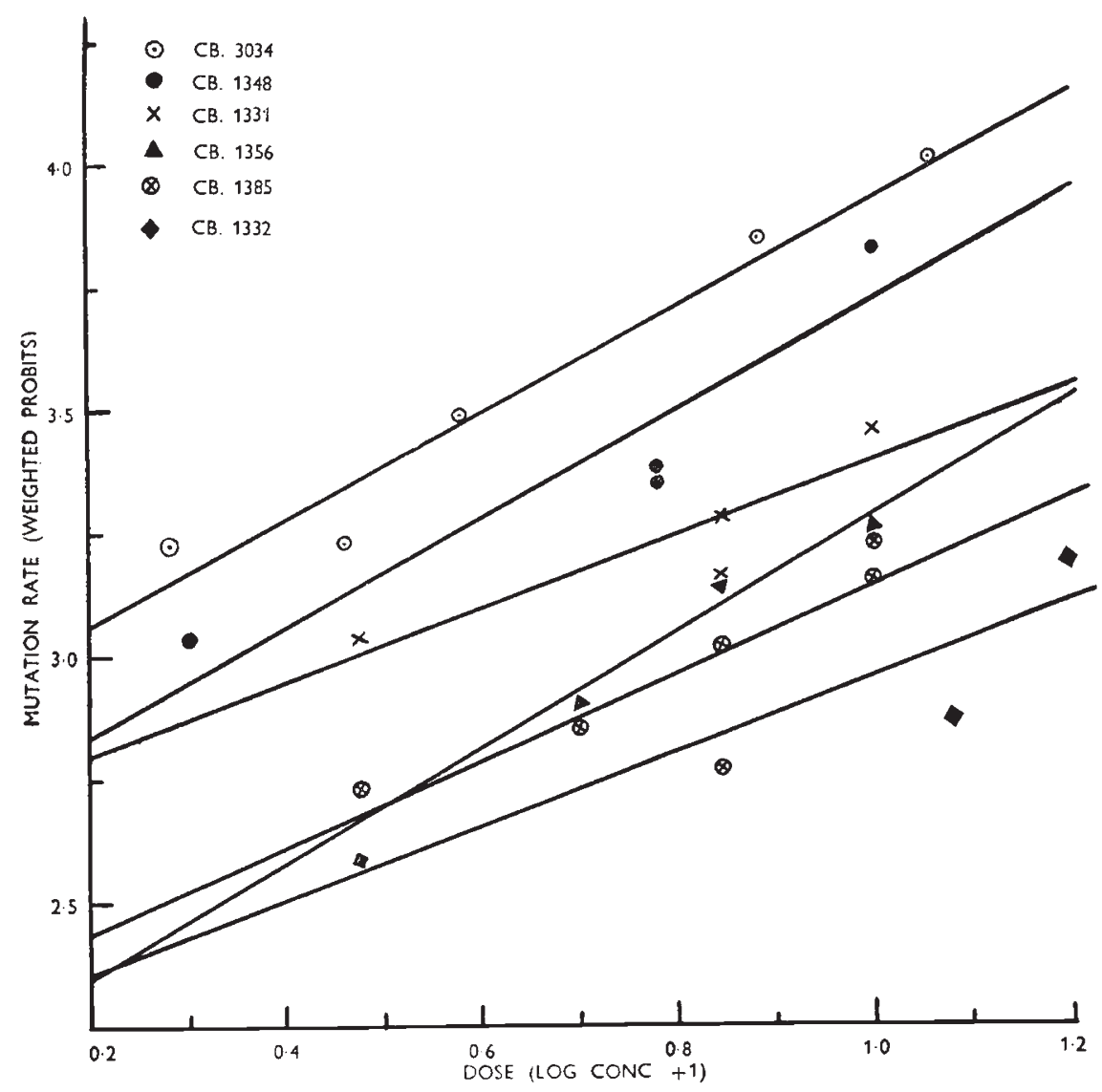

Fig. 2.-The regression of mutation rate in probits on dose in log units, under various " nitrogen-mustards".

be tested when the regression has been calculated for probits on log dose $(\log 0=-\infty)$. An indirect solution was, nevertheless, possible involving the use of the formulæ describing the relationship between the transformed variables (table 4 ). The values of $x$ (in $\log$ units) under the various compounds corresponding to the control mutation rate $(0 \cdot 3$ per cent. lethals or $2 \cdot 2522$ probits) were calculated, together with their standard deviations. These $x$ values were then reconverted to absolute units of concentration. With all compounds it was possible to ascertain that the estimated doses corresponding to the control 
mutation rate, were not significantly different from zero (table 6). There is no evidence, therefore, for a threshold effect as regards mutagenicity under the compounds investigated.

TABLE 6

The estimated dose corresponding to the spontaneous sex-linked recessive lethal rate: 0.3 per cent. or 2.2522 probit units

\begin{tabular}{|l|c|c|}
\hline \multicolumn{1}{|c|}{ Mutagen } & $\begin{array}{c}\text { Estimated } \\
\text { concentration } \\
\left(\times 10^{-2} \mathrm{M}\right)\end{array}$ & $\begin{array}{c}\mathbf{P} \\
\text { (deviation from } \\
\text { zero) }\end{array}$ \\
\hline CB. 3034 & $0.03 \pm 0.03$ & 0.3 \\
CB. I348 & $0.05 \pm 0.04$ & 0.2 \\
CB. 3007, 3025, 3026 & $0.13 \pm 0.13$ & 0.3 \\
CB. I33 & $0.03 \pm 0.09$ & 0.7 \\
CB. I356 & $0.13 \pm 0.23$ & 0.6 \\
CB. I385 & $0.10 \pm 0.21$ & 0.7 \\
CB. I332 & $0.12 \pm 0.25$ & 0.6 \\
\hline
\end{tabular}

\section{CHEMICAL STRUCTURE AND MUTAGENICITY}

From the dose/effect formulæ deduced for the various compounds, the mutation rates in probits corresponding to $\mathrm{Io}^{-2} \mathrm{M}(x=\mathrm{I}$ on the transformation scale) were calculated together with their appropriate standard deviations. The probit values were then converted to the corresponding percentage sex-linked recessive lethal rates. These rates are listed in table 7 and compared with the in vitro chemical

TABLE 7

Mutagenicity in the sperm and chemical reactivity for various " nitrogen-mustards"

\begin{tabular}{|c|c|c|c|}
\hline \multirow{2}{*}{ Mutagen } & \multirow{2}{*}{$\begin{array}{l}\text { Per cent. mutation } \\
\text { rate for an injected } \\
\text { dose of }{ }^{-2} \mathrm{M}\end{array}$} & \multicolumn{2}{|c|}{$\begin{array}{l}\text { Per cent. hydrolysis in } 30 \text { minutes in } \\
\text { I : I acetone-water at } 66^{\circ} \mathrm{C} \text {. }\end{array}$} \\
\hline & & Acid & Sodium salt \\
\hline CB. 3034 & $\mathrm{I} 4 \cdot \mathrm{I} \pm 3 \cdot \mathrm{O}$ & \multicolumn{2}{|c|}{ undetermined } \\
\hline CB. 1348 & $10 \cdot 0 \pm 1 \cdot 8$ & 32 & $4^{2}$ \\
\hline CB. $3007, ' 25, ' 26$ & $5.5 \pm 0.5$ & 22 & \\
\hline CB. $\mathrm{I} 33 \mathrm{I}$ & $5.4 \pm 0.9$ & 17 & 39 \\
\hline CB. 1356 & $4 \cdot 4 \pm 1 \cdot 3$ & 27 & $3^{8}$ \\
\hline CB. ${ }^{2} 385$ & $3.1 \pm 0.8$ & 30 & $\ldots$ \\
\hline CB. 1332 & $2 \cdot 1 \pm 0 \cdot 5$ & 24 & $4^{1}$ \\
\hline
\end{tabular}

reactivity of the chlorine atoms of the "mustards" used, as assessed by the rate of hydrolysis in aqueous acetone (Everett, Roberts and Ross, 1953; Davis, Roberts and Ross, 1955). It is clear that all the compounds are of a very high order of reactivity (under mild conditions), as regards the production of carbonium ions (Ross, 1953). All the compounds are also decisively mutagenic on the sperm, which 
is almost exclusively hereditary nucleoproteins. This strongly suggests a direct interaction between the carbonium electrophilic ions and the nucleophilic centres in the genetic material, as the cause of mutagenicity. It is evident, however, that there is no absolute correlation between chemical reactivity and mutagenicity. Thus, while the compounds listed in table 7 are of roughly the same chemical reactivity, some members of the series give significantly different mutation rates.

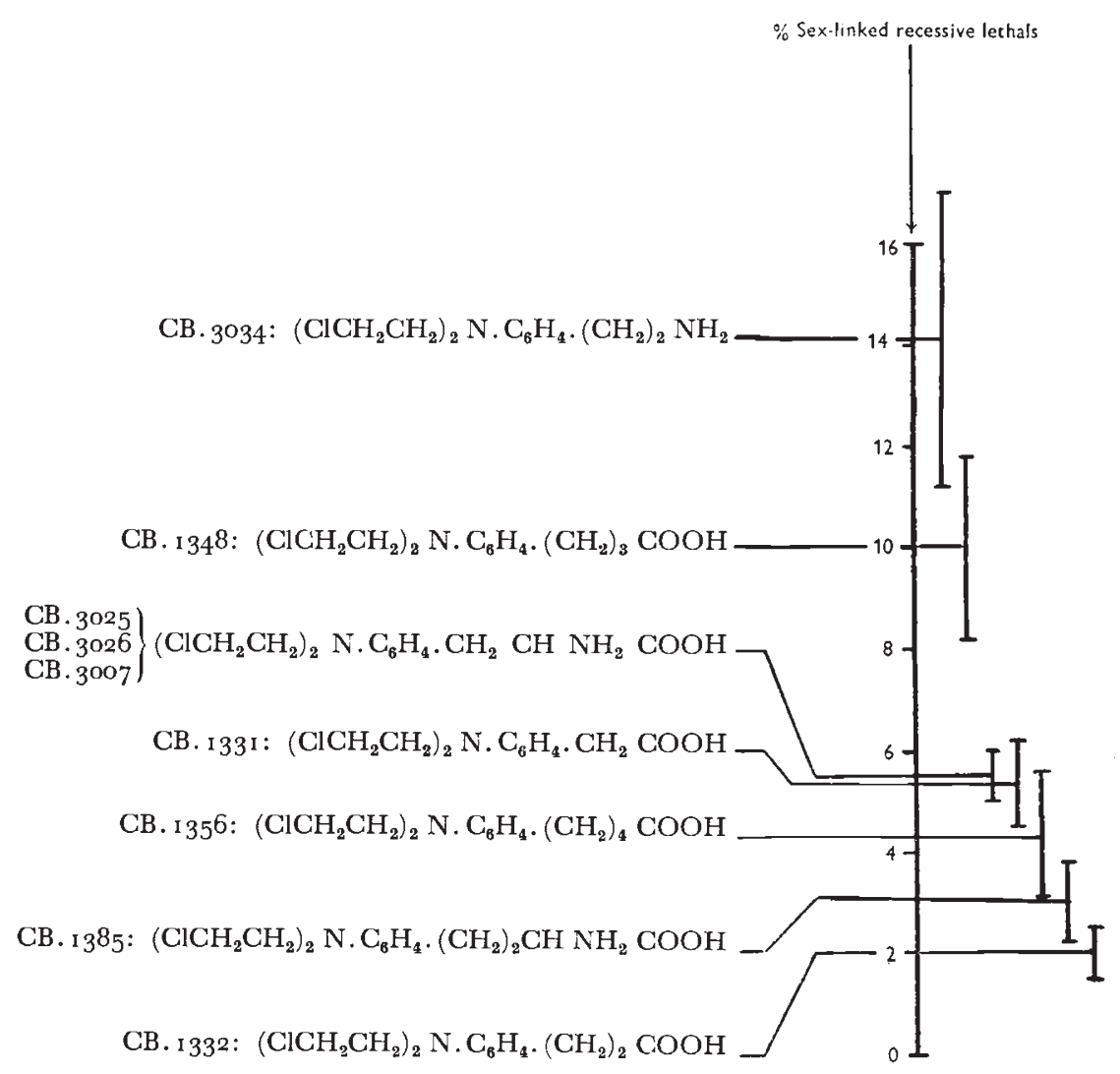

Fig. 3.-Mutagenic potency on the sperm in relation to chemical structure. The sexlinked recessive lethal rate (standard deviation represented by vertical lines) induced by an injected dose of $10^{-2} \mathrm{M}$ under various " nitrogen-mustards".

Fig. 3 is a graphic representation of the mutation rates induced in the sperm by an injected concentration of $1 \mathrm{I}^{-2} \mathrm{M}$ of the compounds studied. The mutagenicity of the carboxylic acid mustards, of general structure (I), varies with the length of the

$$
\left(\mathrm{ClCH}_{2} \mathrm{CH}_{2}\right)_{2} \mathrm{~N} \mathrm{C}_{6} \mathrm{H}_{4} \cdot\left(\mathrm{CH}_{2}\right)_{n} \mathrm{COOH}
$$

acid side chain. The activity is higher when $n$ (in formula $\mathrm{I}$ ) is odd ( $\mathrm{I}$ or 3 ; as in the acetic and butyric acid derivatives: CB. I33 I and I348), than when it is even (2 or 4 : as in the propionic and valeric acid derivatives: CB. $133^{2}$ and ${ }^{1356)}$. It is to be noted, however, 
that while the difference in mutagenicity between the acetic (I, $n=\mathrm{I}$; CB. I33I) and valeric (I, $n=4$; CB. I356) acid derivatives may not be real (since it does not reach statistical significance), there is no doubt that the activity of the butyric derivative ( $\mathrm{I}, n=3$; CB. 1348) is the highest, and that of the propionic acid derivative (I, $n=2$; CB. I332) is the lowest, among the phenylcarboxylic acid mustards. The substitution of the carboxyl group of the propionic acid derivative by an amino group (thus producing the phenylethylamine mustard), had a very gross effect on mutagenicity; the acid (CB. I332) is the weakest while the amine (CB. 3034) is the most active of the tested series.

The introduction of an amino-group on the $\alpha$-carbon of the carboxylic side chain, thus converting the molecule into the corresponding amino-acid mustard (of general formula II),

$$
\left(\mathrm{ClCH}_{2} \mathrm{CH}_{2}\right)_{2} \mathrm{~N} \cdot \mathrm{G}_{6} \mathrm{H}_{4} \cdot\left(\mathrm{CH}_{2}\right)_{n} \mathrm{CH}\left(\mathrm{NH}_{2}\right) \mathrm{COOH}
$$

also alters the mutagenic potency. This substitution resulted in a significantly higher mutagenic activity for the phenylalanine derivative (II, $n=\mathrm{I}$; CB. 3025, 3026, 3007) as compared to the corresponding propionic acid compound (I, $n=\mathrm{I}$; CB. 1332). On the other hand, a comparable amino-group insertion in the butyric acid mustard ( $\mathrm{I}$, $n=3$; CB. 1348) led to a grossly lower mutagenicity in the corresponding amino-acid (II, $n=2$; CB. I385). A consideration of the amino-acids themselves, also indicates the relevance of the length of the acid side chain. The activity of the phenylalanine-mustard (II, $n=\mathrm{I}$; CB. 3025, 3026, 3007) is significantly higher than that of the amino-butyric acid derivative (II, $n=2$; CB. I385).

\section{DISCUSSION}

A consideration of the biochemical and mutagenic properties of a series of alkylating mutagens (including the nitrogen and sulphur " mustards") led to the conclusion that mutagenicity under these agents is probably due to direct alkylation of some DNA " receptors" in the genetic material (Fahmy and Fahmy, 1959). Recent results using ${ }^{35} \mathrm{~S}$ labelled sulphur mustard (Brookes and Lawley, I96o) has yielded strong evidence that the DNA " receptor" involved (under mild conditions in vitro, as well as in some in vivo systems) is the 7-ring nitrogen atom of guanine moeities. In these experiments the extent of the reaction was of the order of I mol. of the " mustard" per DNA molecule (M. wt. $\left.\simeq 2 \times 1 \mathrm{IO}^{6}\right)$.

The alkylation reaction between DNA and the "mustard" would be expected to follow the law of Mass-action. With dilute solutions of the reagent and with excess substrate (sperm heads) this reaction would be expected to proceed linearly with increasing concentration. If single event mutations (sex-linked recessive lethals) could be looked 
upon as the biological consequence of this reaction, a linear relationship between mutation rate and molar dose would be expected. This relationship was shown to hold true for the action of TEM (2:4:6tri(ethyleneimino)-1:3:5-triazine) on post-meiotic sperm (Fahmy and Bird, 1953), as well as for the action of the present series of nitrogen mustards on mature sperm.

On the hypothesis of mutagenicity through direct alkylation, it would also be expected that the mutation rate in a given cell population, under compounds of roughly the same penetrance, would correspond to their alkylating ability. The closely related series of nitrogen mustards investigated were of roughly the same chemical reactivity, but some showed significantly different mutagenicity on the mature sperm. It was possible to show that the molecular configuration of the non-alkylating (or prosthetic) group is of some relevance.

The exact role of the prosthetic moeity of the mutagenic molecule on biological potency is still obscure. Since the variation occurred in the response of the anabolically inert sperm, it is probably independent of the mechanisms of metabolic transport. Differential penetrance of the various compounds into the sperm heads (as a function of permeability and other physiological factors), though it cannot altogether be excluded, is unlikely to have played a major role. The compounds differ from each other by various substitutions involving small radicals and are of comparable physical properties and molecular size. It is certain, however, that the various molecular configurations studied could confer different electrical charges to the " mustard" molecules in solution. This could influence the alkylation reaction between the "mustards" and DNA, through electrostatic phenomena. In vitro reactions (Alexander, Cousens and Stacey, 1957) showed that "mustards" with a zwitterion (i.e. carrying a tve and a -ve charge, like the phenylalanine derivative) reacted readily with DNA, while those with negative charge (the carboxylic mustard, through giving ionised carboxyl groups) failed to react either partially or completely. The amine-mustard (CB. 3034) gives in solution $+v e$ ammonium ions, which may account for its much higher mutagenicity than the corresponding negatively charged carboxylic acid derivative (CB. 1332).

There remains the interesting possibility that the variation in mutagenicity, through changes in the prosthetic group, may be a truly chemical phenomenon, due to reactions with different sites along the chromosomes with varied susceptibility. This could be visualised to arise through steric phenomena governed by the molecular configuration of the mutagen relative to the gene. The longitudinal differentiation of the chromosomes into genes of different function, necessitates some variation in genic structural configuration. This could conceivably result in variation in the "exposure" of the DNA alkylation receptors (especially the DNA bases) to alkylating agents of different molecular structure. As a consequence, compounds of 
the same potential alkylating power (as with the present series) could produce differential mutability, both quantitatively and qualitatively. Whatever the chemical explanation, it is now certain that various alkylating mutagens do produce differential mutagenic effects, at least as regards the induction of point-mutation visibles (Fahmy and Fahmy, I959). Even among the chemically related series of "mustards" analysed in this communication, there was a decisive difference in the ratio of visible to lethal mutations induced in the same sample of treated X-chromosomes under the derivatives of aminoacids as compared to those of carboxylic-acids (Fahmy and Fahmy, 1956 and $1960 b$ ). This would seem to suggest that different prosthetic groups may be influencing the chemical reactions leading to mutagenicity and not merely varying the degree of penetrance into the treated nuclei.

\section{SUMMARY}

The relationship between the dose injected (around the testes of the adult), and the mutation rate detected in the sperm, has been investigated for a series of aryl-2-chloroethylamines (nitrogen mustards) with different prosthetic groups: amino-acids, carboxylic acids and amines. With all compounds there was a linear relationship between the molar dose injected and the sex-linked recessive lethal rate induced. This is compatible with the chemical evidence that the above "mustards" act through direct alkylation of some of the DNA receptive groups. At the same molar concentration $\left(\mathrm{IO}^{-2} \mathrm{M}\right)$, however, significant differences in the mutagenicity of the various compounds were detectable, and they were not strictly correlated with the in vitro reactivity of the chlorine atoms of the chloroethyl-groups. The molecular configuration of the non-alkylating (prosthetic group) was relevant to mutagenic efficiency. The role of the alkylating and prosthetic moeities of the "mustard-molecule" to mutagenesis is discussed.

Acknowledgments.-We are indebted to Professor A. Haddow, F.R.s. for his interest and to our colleagues of the Chemistry Department, particularly Professor F. Bergel, F.R.s., Dr W. C. J. Ross and Dr J. A. Stock for the supply of the mutagens used and for their helpful discussion.

This investigation has been supported by grants to the Chester Beatty Research Institute (Institute of Cancer Research : Royal Cancer Hospital) from the Medical Research Council, the British Empire Cancer Campaign, the Jane Coffin Childs Memorial Fund for Medical Research, the Anna Fuller Fund and the National Cancer Institute of the National Institutes of Health, U.S. Public Health Service.

\section{REFERENCES}

AleXANDeR, P., COUSEnS, S. F., AND STACEY, K. A. I957. The reactions of the mutagenic alkylating agents with proteins and nucleic acids. Ciba Found. Symp. on Drug Resistance in Micro-organisms, pp. 294-318.

Bergel, F. I955. Attempts at chemotherapy of malignant diseases. Four. Pharm. and Pharmacol., 7, 297-3 I3. 
BIRD, M. J., AND FAHMY, O. G. I 953. Cytogenetic analysis of the action of carcinogens and tumour inhibitors in Drosophila melanogaster. I. I : 2, 3:4-Diepoxybutane. Proc. Roy. Soc. London B, I4o, 556-578.

BROOKES, P., AND LAWLEY, P. D. I 960 . The reaction of mustard gas with nucleic acids in vitro and in vivo. Biochem. $\mathcal{F}$. (in press).

DAVIS, W., ROBERTS, J. J., AND ROSS, w. C. J. I955. Aryl-2-halogenoalkylamines. XIII, Chloroethylamino-derivatives of some phenoxyalkanoic acids and some substituted $\alpha$-amino-acids. 7. Chem. Soc., pp. 89o-895.

EVERETT, J. L., ROBERTS, J. J., AND ROSS, W. C. J. I953. Aryl-2-halogenoalkylamines. XII. Some carboxylic derivatives of NN-di-2-chloroethylaniline. 7. Chem. Soc., pp. 2386-2392.

FAHMY, O. G., AND BIRD, M. J. 1953. Chromosome breaks among recessive lethals induced by chemical mutagens in Drosophila melanogaster. Heredity, 6 (supp.), I 49-I 59 .

FAHMY, O. G., AND FAHMY, M. J. I955. Cytogenetic analysis of the action of carcinogens and tumour inhibitors in Drosophila melanogaster. IV. The cell-stage during spermatogenesis and the induction of intra- and inter-genic mutations by $2: 4: 6$-tri-(ethyleneimino)-I $: 3: 5$-triazine. 7. Genet., 53, 563-584.

FAHMY, O. G., AND FAHMY, M. J. I956. Cytogenetic analysis of the action of carcinogens and tumour inhibitors in Drosophila melanogaster. V. Differential genetic response to the alkylating mutagens and X-radiation. 7 . Genet., 54, I 46-164.

FAHMY, O. G., AND FAHMY, M. J. I959. Differential gene response to mutagens in Drosophila melanogaster. Genetics, 44, I I 49-I I 7 I.

FAHMY, O. G., AND FAHMY, M. J. I960a. Cytogenetic analysis of the action of carcinogens and tumour inhibitors in Drosophila melanogaster. VI. The mutagenic cell stage response of the male germ line to the " nitrogen-mustard" derivatives of amino-acids, carboxylic acids and amines. Genet. Res., I, I 73-188.

FAHMY, O. G., AND FAHMY, M. J. I $960 b$. Cytogenetic analysis of the action of carcinogens and tumour inhibitors in Drosophila melanogaster; VII. Differential induction of visible to lethal mutations by related "nitrogen-mustards". Genetics, 45, 4 I $9-438$.

Fisher, R. A., AND yates, F. 1953. Statistical Tables for Biological, Agricultural and Medical Research. Oliver and Boyd, Edinburgh.

Haddow, A. I955. The biochemistry of cancer. Ann. Rev. Biochem., 24, 689-742. mather, K. I949. Statistical Analysis in Biology. Methuen and Co. Ltd., London. Ross, w. C. J. I953. The Chemistry of Cytotoxic Alkylating Agenis. Advances in cancer research, Vol. I, Academic Press, New York. 